\title{
Christopher W. Tindale, Fallacies and Argument Appraisal
}

\section{Cambridge University Press, Cambridge, 2007, xvii + 218 pp. Series: Critical Reasoning and Argumentation}

\author{
Erik C. W. Krabbe
}

Published online: 9 September 2008

(C) The Author(s) 2008. This article is published with open access at Springerlink.com

\section{Purpose and Character of the Book}

This textbook by Christopher Tindale is the second volume in the series Critical Reasoning and Argumentation, which series aims at providing up to date introductory texts for use in one-semester courses with an emphasis on dialogue and rhetoric. The first volume to appear in this series was Douglas Walton's Fundamentals of Critical Argumentation (2006), to which Tindale's book has been designed as a companion, though it could also be used besides another argumentation text or on its own in a course dedicated to the study of fallacies.

In the preface the author states (p. xiii) that 'the rationale behind this volume is to introduce students to the study of fallacy by means of the latest research in the field, along with some standard ideas that have remained relevant since the time of Aristotle.' Thus this textbook aspires to leave behind the usual approach of labeling and briefly describing each fallacy, and to do so by recognizing the complexity of fallacies as failed instances of good strategies of argumentation that can only be appropriately evaluated when due consideration is given to the context of argument or dialogue in which the alleged fallacy occurs. Accordingly, 'any instance or suspected instance of one should be treated as a unique case' (p. xvi).

Notwithstanding the conciseness of this book, the author manages to get the message across and to illustrate this approach by discussing more than twenty-five types of fallacy, comprising the most frequent and the most illustrative.

Typically, a chapter or part of a chapter dealing with a particular type of (potential) fallacy runs through the following stages:

E. C. W. Krabbe (西)

Faculty of Philosophy, University of Groningen, Oude Boteringestraat 52, 9712 GL, Groningen,

The Netherlands

e-mail: e.c.w.krabbe@ rug.nl 
(1) An introduction giving a general idea of the fallacy type and some of its history, and most often presenting a legitimate argumentative strategy of which the fallacy constitutes a kind of aberration.

(2) Some cases that show up particular problems with the strategy.

(3) Discussion of various ways to deal with the fallacy, also illustrated by cases.

(4) A short list of critical questions that help to evaluate cases in which the occurrence of the fallacy may be suspected, followed by a more detailed explanation of these questions.

(5) A summary.

(6) Exercises, in which the student is asked to evaluate cases according to the discussion and the critical questions that went before. Evaluating here means more than labeling: in order to do justice to the discussion and the questions one is to write a short evaluative essay and to argue for any position one takes.

\section{General Comments}

This book will be appreciated by many. It courageously takes serious the idea that students should learn to see the complications inherent in arguments as they appear in specific contexts. It nicely connects with contemporary research and provides many references to help those that look for more. The book is attractive, wellstructured, and often captivating. It contains splendid up-to-date case material, both in the text and in the exercises.

But does it replace the labeling approach? I rather think it presupposes, and partly incorporates, the labeling approach. For, preliminary to a detailed evaluation that takes in background and context, one needs to determine whether there is any suspicion of fallaciousness, and if so of what kind. That is, an argument must, in order to be evaluated, first be labeled, not as this or that fallacy, but as potentially this or that fallacy (or as belonging to an argumentative strategy of which such and such fallacies are aberrations). After that, one may proceed to see which fallacy is actually committed (if any).

It is a pity that no examples are given of fully elaborated exercises. This makes it hard for students to decide what exactly is expected of them. A few examples would solve this problem. Perhaps they can be provided on the internet.

The critical questions form the corner-stone of the whole approach. But there are two fallacies for which they are missing: Irrelevant Conclusion and the Fallacy of Argument from Consequences. Ad verecundiam has two sets of questions. The second set is mainly a refinement of the first, but leaves out the second question of the first set ('Did the authority make the attributed claim?', p. 133). So one actually needs both sets.

Among the references, there are many to the pragma-dialectical standard theory, but none to the pragma-dialectical integrated theory (the theory of strategic maneuvering) that incorporates rhetorical insights (van Eemeren and Houtlosser 1999; 2002). This is a bit surprising, since the author is clearly concerned with strategies and with contextual settings, as is the integrated theory. 


\section{Specific Comments}

The list below contains a number of more detailed comments that could be useful for instructors using the book or for preparing a second edition.

1. (p. 12) According to Tindale not all fallacies are misuses of legitimate strategies, and he adduces Straw Man as a counterexample. 'There seems no clear way that we can judge this the counterside to some legitimate argumentative strategy, unless we conjure up something trivial such as "Real Man".' But Real Man is not so trivial, considering how hard it is to correctly explicitize the implicit elements in one's opponent's position. Straw Man can be seen as a 'derailment' of such explicitization strategies.

2. (p. 43) In a passage discussing the difficulties of applying rules for validity and invalidity, there is a surprising reference to Gerald Massey, which says that he was 'concerned that we can rarely decide that premises are all true and the conclusion false because we are not clear how to prove this.' That is, according to Massey, what he calls 'the trivial logic-indifferent method' can rarely be applied to show invalidity. But since this method (showing the premises to be all true and the conclusion false) is not the most common way to show that arguments are invalid, the reader may be at a loss about what Massey's concern implies for the possibilities of establishing invalidity. For this, one needs to know that, according to Massey, there is no other method to do so that has theoretical legitimacy. But familiarity with Massey's position can not be assumed in an introductory text. Also, it should not be taken for granted that Massey was right. Actually, Massey's claim can be refuted: there are other bona fide methods of establishing invalidity (Krabbe, 1995). Which is not to say that Tindale's point about the difficulties of applying rules for validity and invalidity is mistaken.

3. (pp. 44, 45) When explaining Aristotle's theory of the syllogism, Tindale notes that there are not only valid, but also 'false or invalid syllogisms'. Though this way of speaking is contrary to Aristotle's parlance, it conforms to contemporary usage of these terms (I would much prefer 'invalid' to 'false', though). However, the quote from Aristotle that follows ("A false syllogism cannot be drawn from true premises') is incomprehensible. Suspecting a misprint, I searched at the indicated location (Anal. Pr. II.16, 64b), but failed to locate the quote. Perhaps the intention was to refer to an earlier passage (Anal. Pr. II.2, 53b) in which Aristotle claims that from true premises one cannot syllogize a falsehood (i.e., validly draw a false conclusion). But this passage does nothing to show that there are, in Aristotle's terminology, invalid syllogisms. When we would say that there was an invalid syllogism, Aristotle would say that there was no syllogism.

4. (p. 60) The case of the dog and the puppies (Plato's Euthydemus 298D-E) is described as 'a classic case of Equivocation'. There is nothing against treating this case from that angle, but it should be mentioned that Aristotle does not refer to it as a fallacy dependent on language, but as a fallacy of accident, 
which is one of the types of fallacy not depending on language ( $S E 24,179$ a 34-35, b 14-15).

5. (p. 63) I have some doubts about the way the critical questions for Equivocation have been formulated. We can say that terms or phrases retain or do not retain their meaning, but can this be said for concepts? Can concepts 'have a shift in meaning' as is written lower on the same page? Rather it seems that concepts are meanings and that a term shifts in meaning when it starts to denote another concept. But if concepts are meanings, then they do not retain their meaning, nor do they shift in meaning. (Of course there are other concepts of 'concept' the author could wish to put forward.) In the second critical question ('Does any shift of meaning indicate that the conclusion fails to prove what it was supposed to prove?') the word 'conclusion' should perhaps be replaced by 'argument'.

6. (pp. 63, 64) Equivocation problems in the premises are deemed less serious than those that involve the conclusion. I see no reason for this. Take, for instance, the problem of an ambiguous middle term, where different senses for the two occurrences are needed to make each premise acceptable, but an identical sense is needed to make the reasoning valid. In some cases this cannot be remedied.

7. (p. 76) Charles Hamblin's identification of the origins of Begging the Question has been distorted when the situation is described as one in which 'one person asks another to grant a certain premise on which to build a point, but then proceeds to act as if the granted premise has actually been proved.' Hamblin writes: 'The Fallacy consists in asking to be granted the question-atissue, which one has set out to prove' (Hamblin, 1970, p. 33). Accordingly, the fallacy is committed by the Questioner, when asking for the point to be proved (from granted premises) to be granted itself as a premise. This precedes the syllogism that 'proves' the point.

8. (p. 118) Among the examples of reasonable uses of ad ignorantiam the case of scientific disconfirmation (a hypothesis being tested with a negative result) is less than convincing. Not because it would be an unreasonable kind of reasoning, but because it is not an Argumentum ad ignorantiam, being based straightforwardly on knowledge (the outcome of the test) rather than a lack of knowledge. A better example is obtained, in a Popperian way, when a hypothesis has been thoroughly tested and passed all tests ('has proved its mettle'). This does not prove the hypothesis, but the acceptance of the hypothesis is then based upon a reasonable kind of ad ignorantiam.

9. (pp. 133, 135) The third critical question for ad verecundiam on p. 133 ('Are the authority and claim made relevant to the subject matter?') covers two issues: (1) Does the claim made by the authority belong to this authority's field of expertise? (2) Is the claim relevant for the point the arguer wants to prove? The question is reformulated more clearly on p. 135. Nevertheless, it remains confusing to have these two issues in one question. Moreover, the second issue does not belong to the argument from authority proper but to the argument leading from the authority's claim to the arguer's ultimate point. 
10. (pp. 155-157) It is good to have a section on The Gambler's Fallacy and related fallacies, and to discuss the work of Tversky and Kahneman, but their concepts (representativeness, availability, adjustment, anchoring) should be better explained so that the reader may apply them to a case like $8 \mathrm{C}$.

After this list, in which some of the weaker spots in the text were discussed, one may have the false impression that this text is not a good choice for use in the classroom. But I do, on the contrary, think that it would be a good choice. Weak spots, moreover, can be repaired. They can also occasion stimulating discussions.

Open Access This article is distributed under the terms of the Creative Commons Attribution Noncommercial License which permits any noncommercial use, distribution, and reproduction in any medium, provided the original author(s) and source are credited.

\section{References}

van Eemeren, F.H., and P. Houtlosser. 1999. Delivering the goods in critical discussion. In Proceedings of the Fourth International Conference of the International Society for the Study of Argumentation, ed. F.H. van Eemeren, R. Grootendorst, J.A. Blair, and C.A. Willard, 163-167. Amsterdam: Sic-Sat.

van Eemeren, F.H., and P. Houtlosser. 2002. Strategic manoeuvring in argumentative discourse: a delicate balance. In Dialectic and Rhetoric: the Warp and Woof of Argumentation Analysis, ed. F.H. van Eemeren, and P. Houtlosser, 131-159. Dordrecht: Kluwer. Argumentation Library 6.

Hamblin, C.L. 1970. Fallacies. London, Methuen. Reprinted in 1986, Newport News, VA: Vale Press. Krabbe, E.C.W. 1995. Can we ever pin one down to a formal fallacy? In Proceedings of the Third ISSA Conference on Argumentation (University of Amsterdam, June 21-24, 1994), II: Analysis and Evaluation, ed. F.H. van Eemeren, R. Grootendorst, J.A. Blair, and C.A. Willard, 333-344. Amsterdam: Sic Sat, International Centre for the Study of Argumentation. Also published in Cognitive Patterns in Science and Common Sense: Groningen Studies in Philosophy of Science, Logic, and Epistemology, ed. T.A.F. Kuipers and A.R. Mackor, 151-164, Amsterdam \& Atlanta, GA: Rodopi, 2005 (Poznan' Studies in the Philosophy of the Sciences and the Humanities 45); and in Logic and Argumentation, ed. J. van Benthem, F.H. van Eemeren, R. Grootendorst, and F. Veltman, 129-141, Amsterdam, etc: North-Holland, 1996 (Koninklijke Nederlandse Akademie van Wetenschappen, Verhandelingen, Afd. Letterkunde, Nieuwe Reeks, deel 170). 